\title{
RADIOCARBON CONCENTRATION IN THE ATMOSPHERE: 8000-YEAR RECORD OF VARIATIONS IN TREE RINGS \\ FIRST RESULTS OF A USA WORKSHOP
}

\author{
JEFFREY KLEIN*, JUAN CARLOS LERMAN**, \\ PAUL E DAMON**, and TIMOTHY LINICK***
}

Radiocarbon dates calculated from the ratio of modern carbon-14 activity and sample activity and the half-life of carbon- 14 need to be calibrated to compensate for temporal variations in the concentration of carbon-14 in the atmosphere. Development of a suitable calibration scheme has been an ongoing process of the last twenty years, ever since the discovery of variations in historical times of the atmospheric radiocarbon content which parallel climatic and solar phenomena (de Vries, 1958; 1959) and the recent depletion due to industrial effects (Suess, 1955).

The various laboratories responsible for the retrospective estimation of atmospheric radiocarbon concentration by precise measurement of carbon-14 activity in tree rings of known age, each have produced one or more calibration schemes (Damon, Long, and Wallick, 1972; Damon, Long, and Ferguson, 1974; Ralph and Michael, 1970; Ralph, Michael, and Han, 1973; Michael and Ralph, 1972; Stuiver and Suess, 1966; Suess, $1967 ; 1970)$ as have other independent researchers (Clark, 1973; 1975; Clark and Renfrew, 1972; Lerman, Mook, and Vogel, 1970; McKerrel, 1975; Olsson, 1970; Switsur, 1973; Wendland and Donley, 1971). The assumptions underlying these calibrations have varied, and consequently, the results have differed. Consensus has slowly emerged, recognizing a long-term change in the carbon-14 inventory of nearly 10 percent with a period of the order of 10,000 years. However, differences between the various calibrations have continued, stemming from the manner in which the available data were handled for the estimation of the shorter period secular fluctuations.

Currently, there are approximately 1200 measurements on samples of known age, principally Pinus longaeva and Sequoia gigantea (bristlecone pine and giant sequoia), from the southwestern United States (fig 1). These measurements span 8000 years with each sample representing an average of ten years' tree growth. More data exist in the European absolute and floating tree-ring chronologies but, for reasons that will be explained later, have not been included directly in the analysis reported here.

Because there are comparatively few replicate measurements (only 212), and even fewer replicate measurements involving two or more laboratories ( 30 for 2,15 for 3 ), it has been difficult to estimate exactly

* Department of Physics and Radiocarbon Laboratory, University of Pennsylvania, Philadelphia, Pennsylvania 19104

** Laboratory of Isotope Geochemistry, Department of Geosciences, University of Arizona, Tucson, Arizona 85721

*** Mt Soledad Radiocarbon Laboratory, University of California, San Diego, California 92037 
the precision of measurement of specific activities. However, it is clear that this precision is somewhat less than that quoted by any of the laboratories (eg, Damon, 1970; Currie, 1972; Clark, 1975; 1979). In addition, a few outliers exist in the data set, measurements that could not possibly be representative of the atmospheric carbon-14 concentration at the time to which they have been assigned. These factors have made many researchers cautious in their estimation of short term variations.

As a result, the various calibration schemes for some intervals of the past have produced calibrated dates that differ by as much as a few hundred years from one another, producing confusion and suspicion on the part of those who use radiocarbon dates. In light of this uncertainty, it was proposed to the US National Science Foundation that a workshop be convened to examine the problems of the calibration of the radiocarbon time scale. This workshop was to address itself to the considerations detailed above, as well as to an examination of possible systematic differences between laboratories and the design of a procedure for updating the calibration as more data become available in the future. The preliminary results of the workshop are described here, while the general goals have appeared elsewhere (Michael and Klein, 1979).

It is not currently possible to describe changes in the radiocarbon inventory by derivation of coefficients in a phenomenological model for any phenomenon except the geomagnetic field. This is due to the lack of data regarding the behavior of the factors influencing the radiocarbon production during the past eight millennia, and the tentative nature of the models linking atmospheric carbon- 14 concentration with geophysical factors. Consequently, one is forced to apply some form of 'robust' estimation (Tukey, 1977; Mosteller and Tukey, 1977; Velleman, 1977) using algorithms which are general enough to accommodate a large class of functions, yet which can be adjusted to take advantage of available information.

Least squares fitting, though subject to many serious limitations, provides more information about the distribution of data around an estimate, and the inherent uncertainties in this estimate, than is easily obtainable from almost any other method. The most serious failings of least squares are sensitivity to outliers and sensitivity to the pathologies of the function set used in estimation; such pathologies as the dominance of large $x$ (independent variable) in the determination of the coefficients of polynomial regressions, and 'end point' effects from Fourier analysis of non-stationary time series. On the other hand, linear regression is fairly independent of requirements on the spacing of the data (unlike moving averages and autoregression which are dependent on equal spacing), and freedom from a dependence on initial guesses as with nonlinear approaches. 


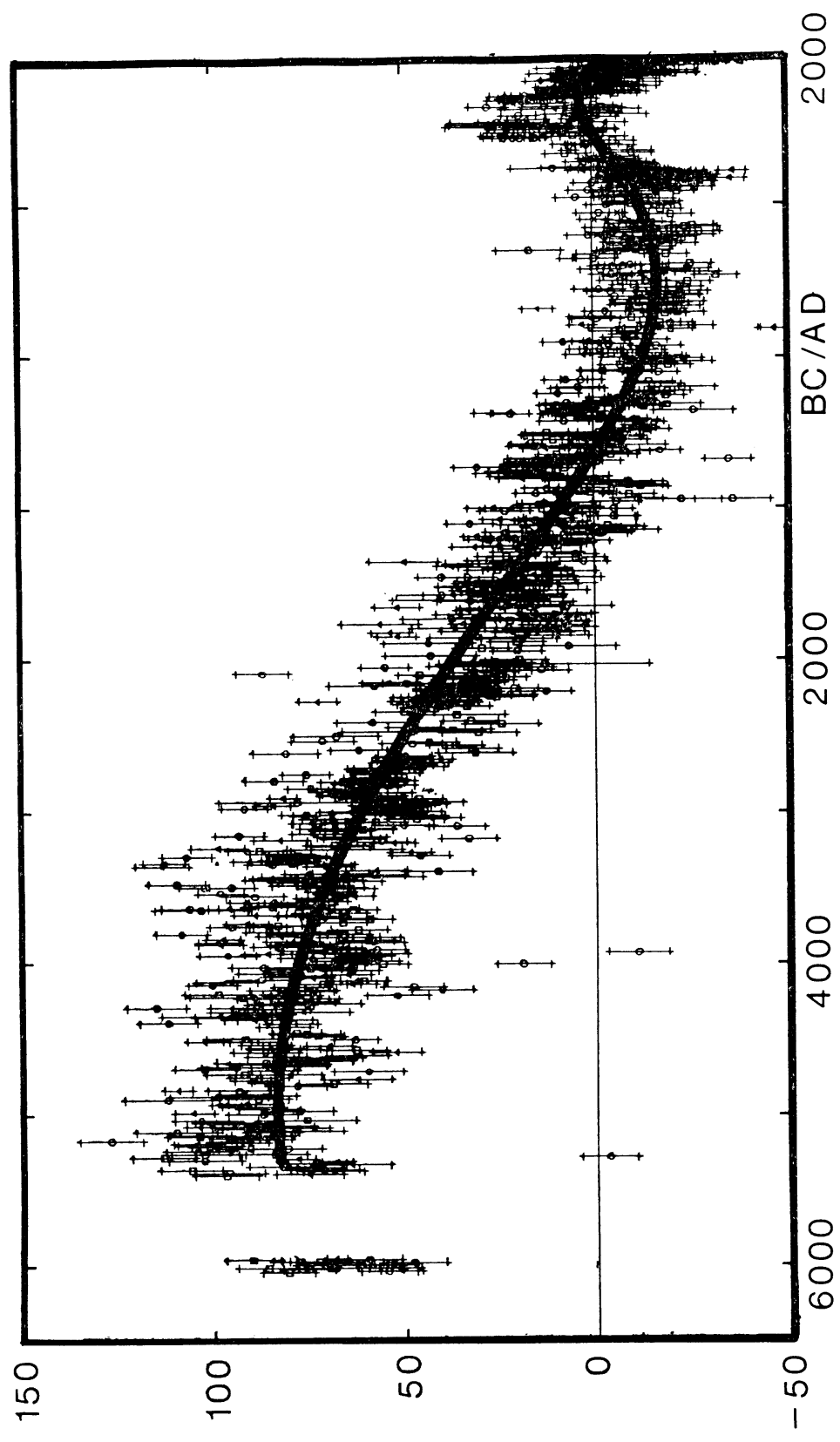

$(0 \%) \nabla$
范苛

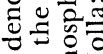

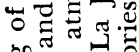

कo

5.

$\rightarrow \pi$

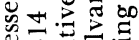

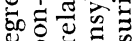

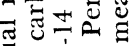

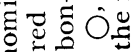

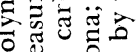

急.

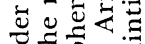

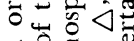

5

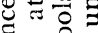

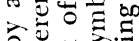

山

-

$\varangle$

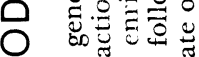

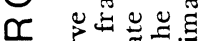

○

Z

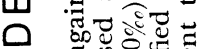

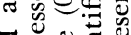

这跤

a

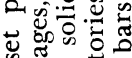

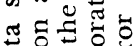

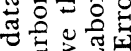

ธ。

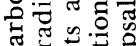

등 응

ฮี

政

氙记言

实的

o 0.

$-1000$

so 5

覀

郘 
Consequently, the Workshop ${ }^{1}$ (Damon and others, 1980) decided to adopt a multistage linear regression procedure based on an algorithm first presented at the Ninth International Radiocarbon Conference at La Jolla in 1976 (Ralph and Klein, 1979).

In outline, the procedure involves a logarithmic compression of the data set to remove the disproportionate weight, given during polynomial regression, to data points with large values in the independent variable, $i e$, age. This results in improved numerical accuracy which is limited by the inversion of the variance matrix, due to its large determinant and roughly equally-sized individual elements. Polynominal regression was chosen to 'detrend' the radiocarbon concentration due its compatibility with the secular growth. Such growth is demonstrated by the 10 percent increase in carbon-14 concentration of 7000 years ago compared to that of the pre-industrial 19th century. The results of the regression are shown in figure 1 . After the data were detrended, the residuals of the data around the trend were Fourier-analyzed in overlapping intervals of 500 years.

After the first regression, outliers, which normally would influence the regression by the square of their residuals divided by the number of 'normal' data points in the interval, were winsorized (Mosteller and Tukey, 1977) so that their effect would be reduced. The winsorization procedure involves replacing points with residuals more than twice as large as the residuals of 80 percent of points, by points with residuals equal to twice the fourth quintile residual.

The order of the Fourier analysis was chosen from a minimum in the F-statistic and from visual inspection of the conformances of the curve to the data. The 500-year regression (shingles) were averaged to minimize end effects. This "welding" was done using a cosine weight equal to one, in the middle of the interval, and to zero, at the ends. This averaged the predicted value of neighboring shingles with the result shown in figure 2 .

${ }^{1}$ Workshop on calibration of the radiocarbon time scale, January 28-February 2, 1979, University of Arizona, Tucson, funded by NSF Grant EAR-817358

Fig 1. (cont'd).

The equation of the trend line in logarithmically compressed coordinates is:

where $\mathrm{x}_{1}$ (scaled) $=\alpha \log _{10}\left(\mathrm{x}_{\mathrm{i}}\right)+\beta$

$$
\mathrm{y}_{\mathrm{i}}(\text { scaled })=\stackrel{6}{\mathrm{\Sigma}} \stackrel{\Sigma}{=} \mathrm{O}^{\mathrm{a}_{\mathrm{n}} \mathrm{x}_{\mathrm{i}}{\text { (scaled })^{\mathrm{n}}}^{\mathrm{n}}}
$$

$\mathbf{x}_{1}$ is the dendro-age expressed in years before $A D 1975$

$$
\begin{array}{ll}
\alpha=0.7746068 & \mathrm{a}_{3}=-1.2495 \\
\beta=-0.202420 & \mathrm{a}_{4}=0.64146 \\
\mathrm{a}_{0}=-.023469 & \mathrm{a}_{5}=0.59100 \\
\mathrm{a}_{1}=1.2057 & \mathrm{a}_{6}=-0.34435
\end{array}
$$

The values $y_{1}$ (predicted age in radiocarbon years calculated with $T_{1 / 2}=5730$ years and origin an $\mathrm{AD}$ 1975) are then obtained from $\mathrm{y}_{1}$ (scaled) by using the formula:

$$
\mathrm{y}_{\mathrm{i}}=\exp \frac{\mathrm{y}_{1} \text { (scaled) }-\beta}{\alpha}
$$




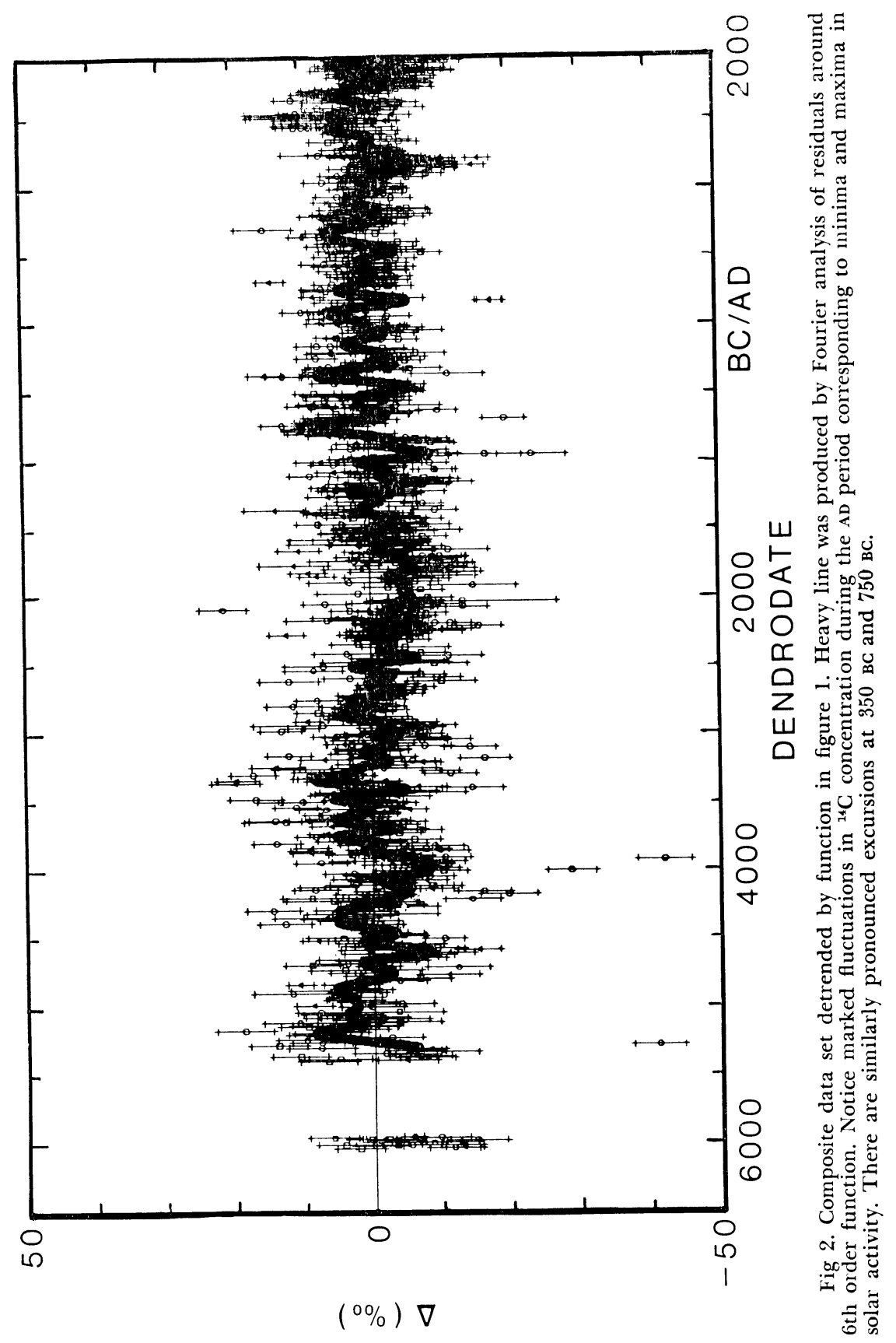


During the analysis of goodness of fit and from plots of the residuals (fig 3) versus individual labs, it became apparent that a systematic difference existed between the laboratories of Arizona and Pennsylvania on the one hand, and La Jolla on the other. This difference was about $6 \%$ (48 years). As a consequence, all the data used in the 'geophysical curve,' the wiggly line shown here in figures of delta carbon-14 versus age, were adjusted to a common mean. Table 1 shows the systematic differences. These values were used to adjust the data. It was decided that similar adjustments would not be made on the calibration table data set, but that larger uncertainties would be included to allow for the uncertainty in standardization which seems to exist even in these precise measurements.

As a test of the robustness of the methods employed here, we performed a series of experiments to study the ability of the Fourier regression to retrieve signals from a noisy environment. We constructed an artificial data set consisting of a pure sine of amplitude 10\% (80 years) with superimposed gaussian noise $(\sigma=6 \%, 50$ years) and with white noise of amplitude $6 \%$ (50 years). Figure 4 shows the result of one of these experiments. The experiments were carried out with several sets of noise of various amplitude and the results of the signal retrieval were satisfactory in all of them. For reasons of space we can only show one of the results here.

As another check of the validity of the regression methods described, comparisions were made with independent data sets. Figure 5 shows the regression curve calculated on the workshop data set plotted against the data from de Jong, Mook, and Becker (1979). Notice the good agreement both in amplitude and in phase, of the variations measured at Groningen, and those calculated here. It was decided at the Workshop that the floating chronologies of European trees would not be included until there was firm dendrochronologic evidence of their exact age, for fear of producing biases due to incorrectly located data sets, and circularity with regard to further wiggle matching. Similar agreement exists between the Workshop data set and that of Stuiver and Quay, 1980) on Pseudotsuga menziezii (Douglas fir) (fig 6).

A more detailed description of the method and results including expanded graphs for the whole time range will be given elsewhere.

TABLE 1

Systematic differences observed between laboratories

\begin{tabular}{lc} 
Laboratory & $\begin{array}{c}\text { Average deviation from } \\
\text { the calculated } \triangle(\%)\end{array}$ \\
\hline Arizona (A) & +3.0 \\
Groningen (GrN) & +2.7 \\
La Jolla (LJ) & -3.2 \\
Pennsylvania (P) & +3.4 \\
Yale (Y) & +3.2 \\
\hline
\end{tabular}

Each data set was adjusted by substracting the values in column 2 . 


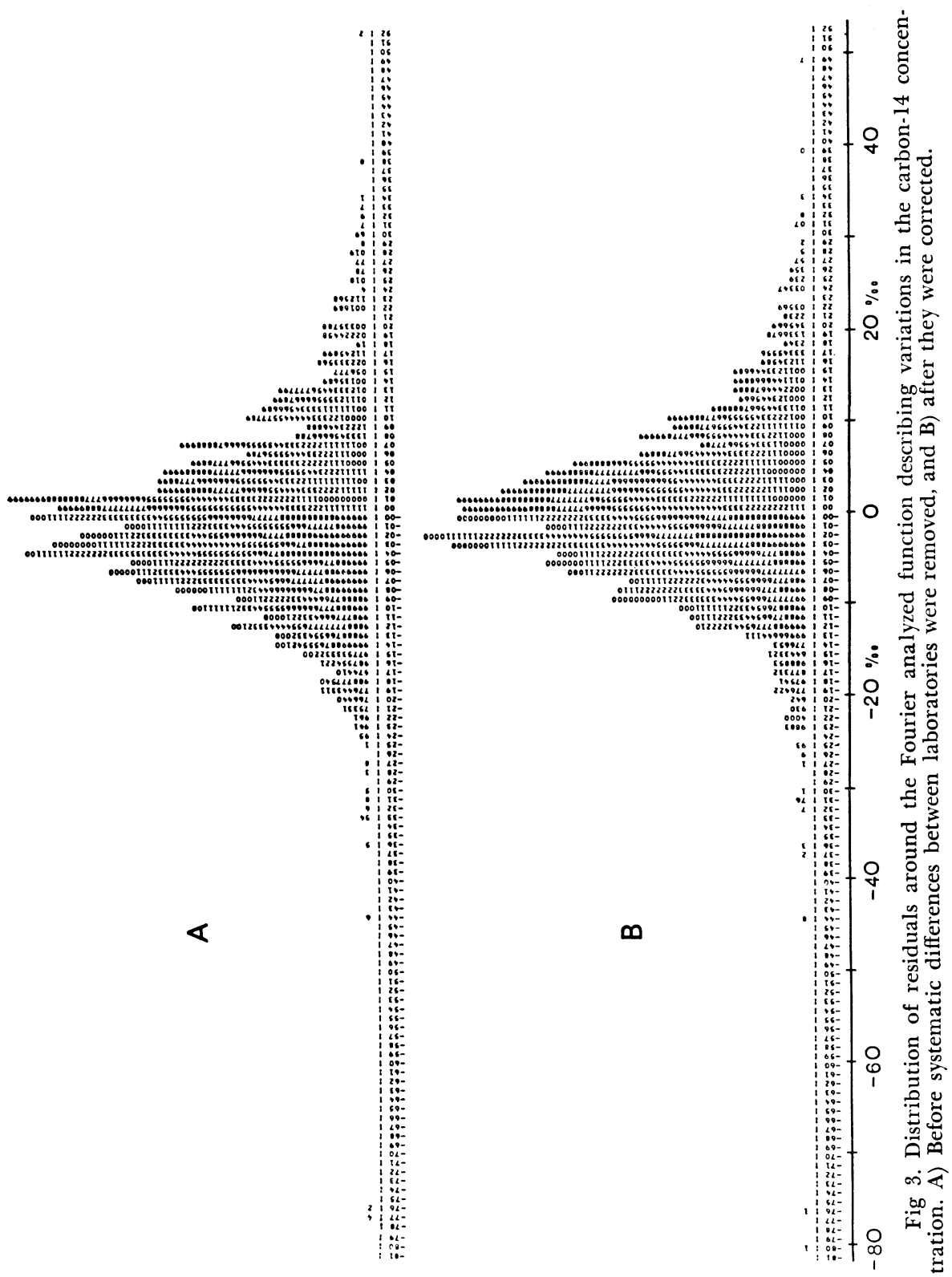




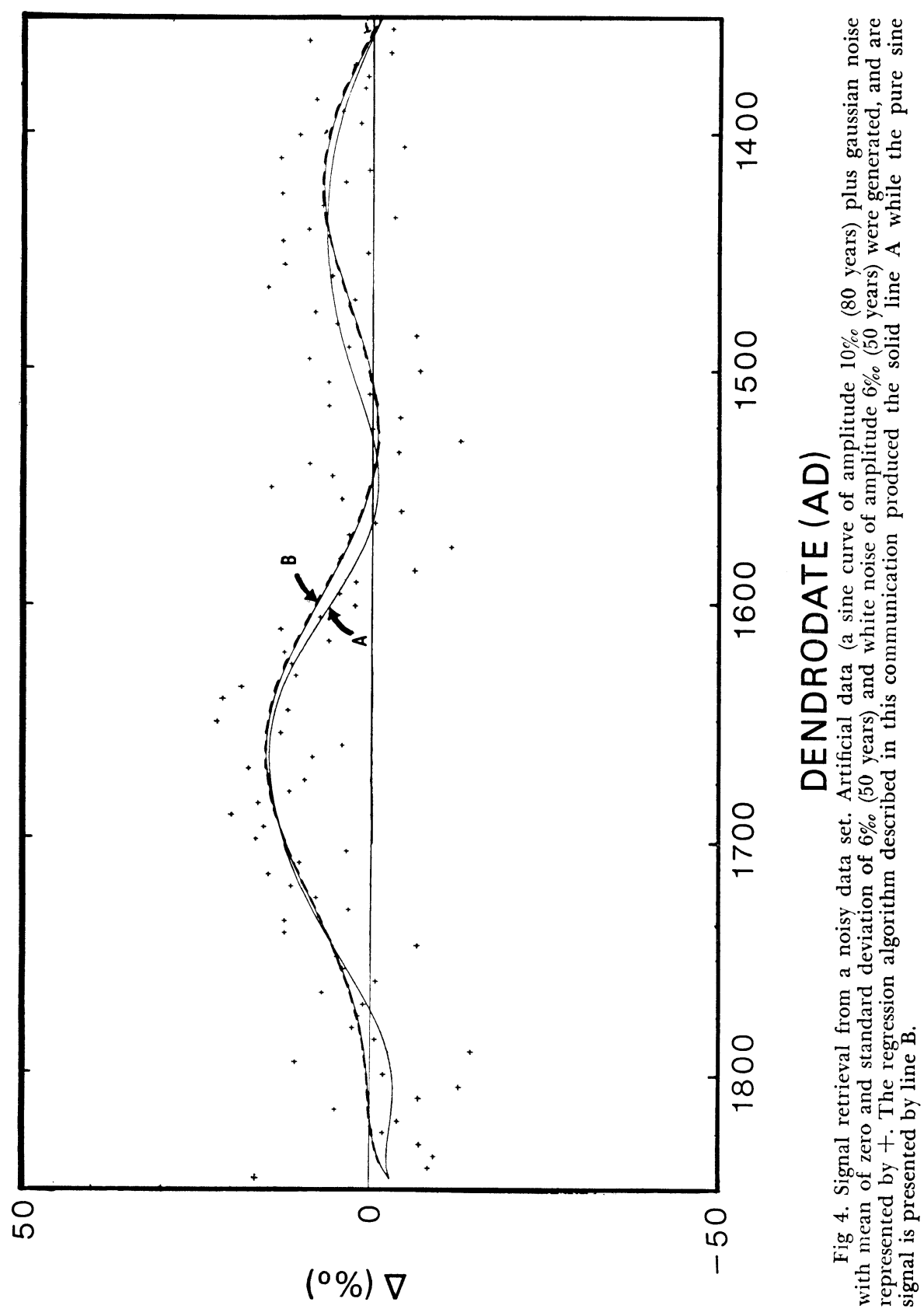




\section{ACKNOWLEDGMENTS}

We thank C W Ferguson for his efforts in the collection, dendrochronologic dating and distribution of bristlecone pine samples, without which this work would not be possible. Much credit goes to Roger Warburton for his assistance in the development of the programs used for generating the regression functions.

We would also like to thank $\mathrm{E} \mathrm{K}$ Ralph and $\mathrm{H}$ E Suess and the staff of the three major laboratories for their radiocarbon analyses of these samples. J W Tukey and R M Clark are acknowledged for their invaluable suggestions during the workshop regarding data analysis.

The work described in this report involved considerable amounts

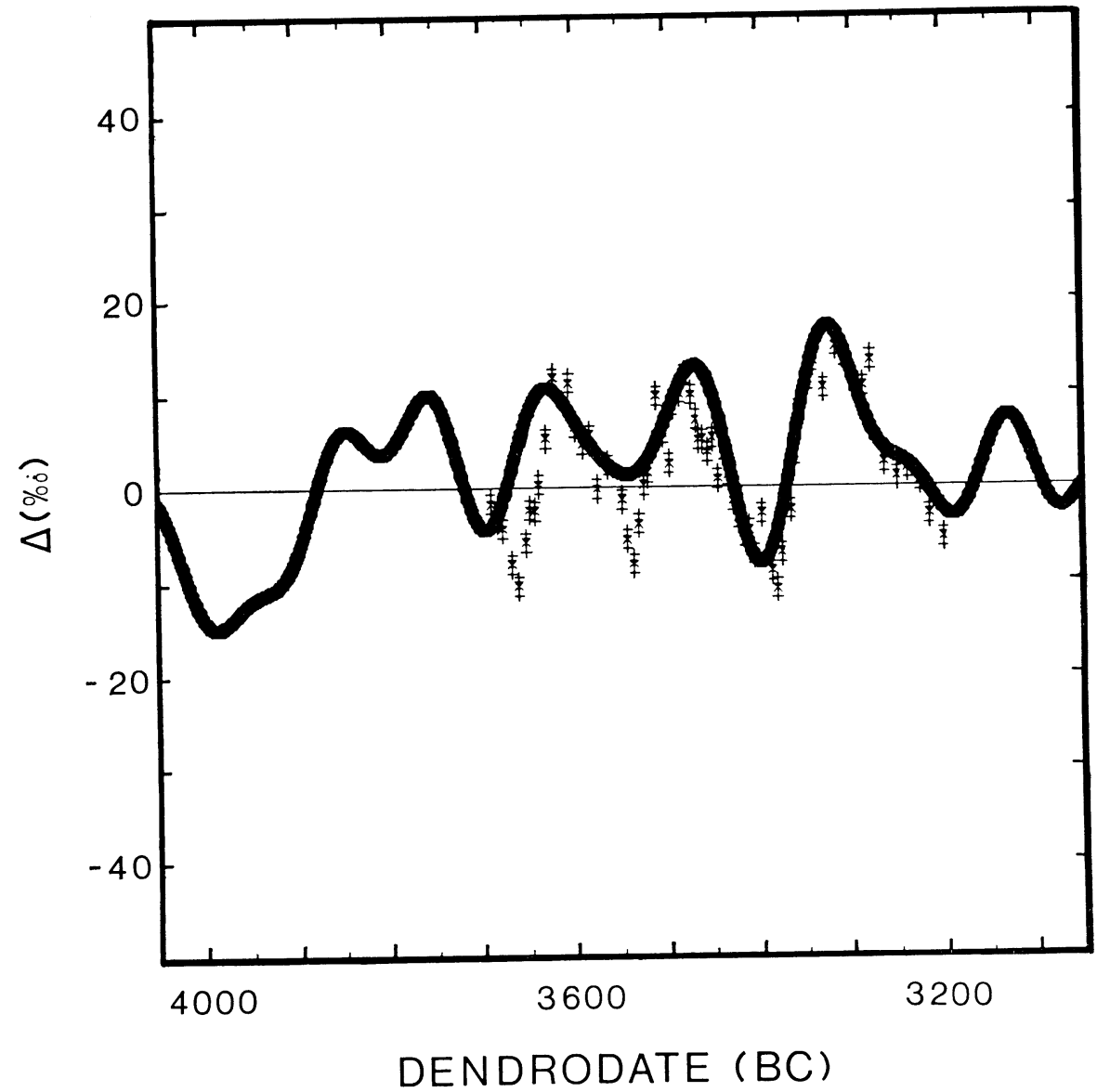

Fig 5. Data from de Jong, Mook, and Becker (1979) detrended as in figure 2 plotted against detrended curve calculated from the composite data set of figure 1 . Notice close agreement of de Jong, Mook, and Becker, data with regressed function, particularly in the more recent half of the interval. The earlier two depletions indicated in that data are more pronounced and the first occurs earlier than that calculated from the composite data set. 
of computing. We are very indebted to the technical, administrative, and managerial staff of the University of Arizona Computing Center. The higher priorities accorded to our work during the Workshop and its aftermath were of fundamental help to us.

We are also indebted to Minze Stuiver for allowing us to display his data from the first millennium BP (unpub).

We would like to thank the National Science Foundation for its generous support of this work through the following grants: EAR-7823584 (Workshop), EAR-78-21813 (Arizona-Radiocarbon fluctuations), EAR-78-15183 (La Jolla), EAR-78-23837 and DES-22233 (Pennsylvania), and EAR-78-04436 (dendrochronology of bristlecone pine, Tree-Ring Laboratory).

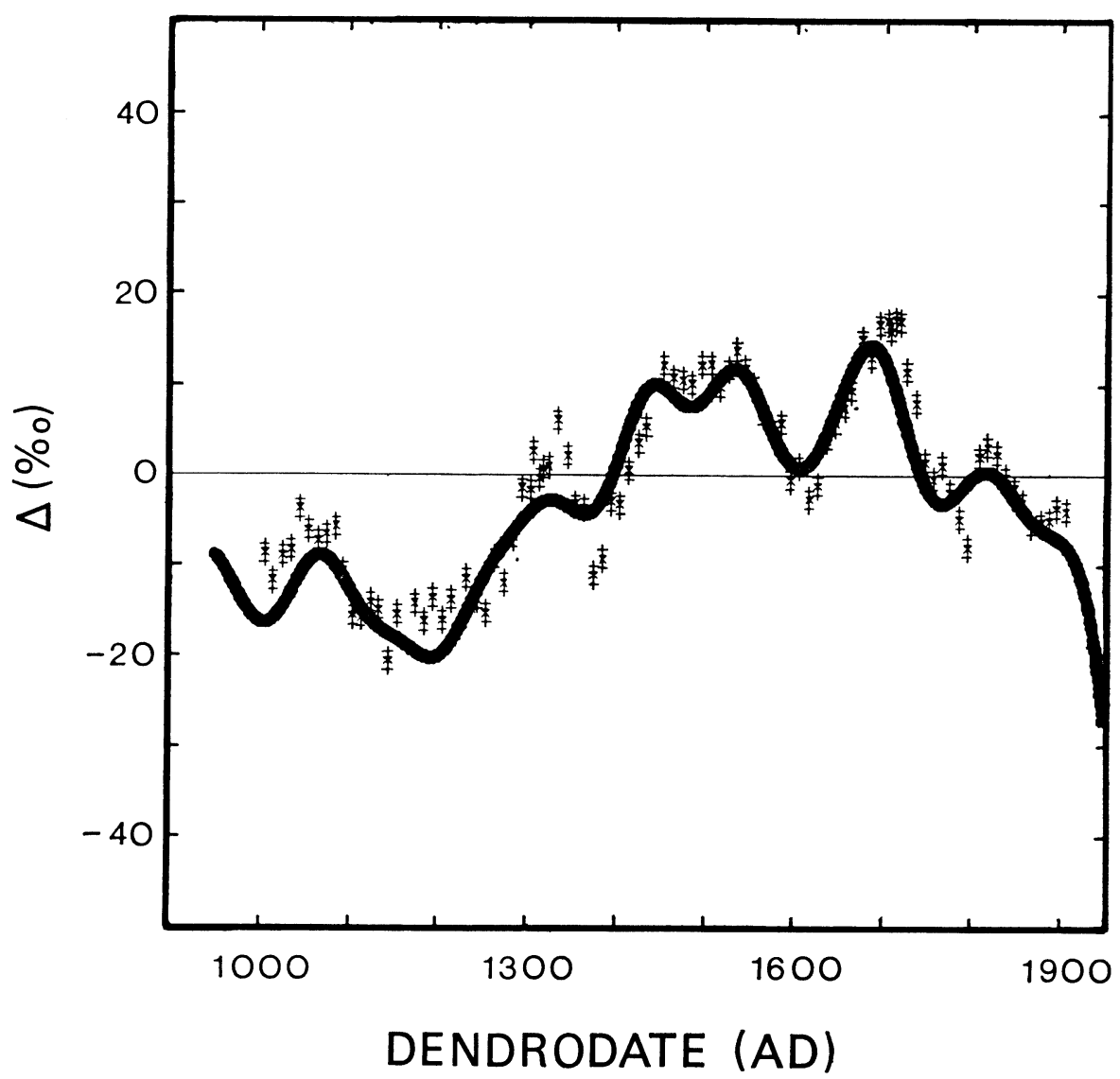

Fig 6. Expanded plot of variations in the atmospheric carbon-14 inventory for the most recent thousand years. Note recent marked depletion of carbon-14 resulting from the industrial production of 'dead' $\mathrm{CO}_{2}$ (Suess effect). Notice also the prominent peaks in carbon-14 concentration due to the increases in neutron flux during the reduced solar magnetic fields of the Maunder, Spörer, and Wolf minima, at AD 1640-1710, AD 1450-1550, and AD 1240-1270, respectively. The so-called Medieval maximum is visible at roughly AD 1250 (DeVries' effects). The data plotted were measured by Stuiver on Douglas fir (Stuiver and Quay, 1980). Notice the good agreement between these independent data, and the regression on the sequoia and bristlecone data. 


\section{REFERENCES}

Clark, R M, 1973, Tree-ring calibration of radiocarbon dates and the chronology of ancient Egypt: Nature, v 243, p 266-270.

1975, A calibration curve for radiocarbon dates: Antiquity, v 49, p 251-266.

1979, Calibration, cross-validation and carbon-14: Royal Statistical Soc Jour, v 142, no. Al, p 47-62.

Clark, R M and Renfrew, Colin, 1972, A statistical approach to the calibration of floating tree-ring chronologies using radiocarbon dates: Archaeometry, $\mathrm{v}$ 14, p 5-19.

Currie, L A, 1972, The evaluation of radiocarbon measurements and inherent statistical limitations in age resolution, in Rafter, $\mathrm{T} A$ and Grant-Taylor, $T$, eds, Internatl radiocarbon dating conf, 8th, Proc: Wellington, Royal Soc New Zealand, p H1-H15.

Damon, P E, 1970, Climatic versus magnetic perturbation of the atmospheric $\mathbf{C}^{14}$ reservoir, in Olsson, I U, ed, Radiocarbon variations and absolute chronology, Nobel symposium, 12th, Proc: New York, John Wiley \& Sons, p 571-593.

Damon, P E, Lerman, J C, Long, Austin, Bannister, B, Klein, Jeffrey and Linick, T W, 1980, Report on the workshop on the calibration of the radiocarbon dating time scale, in Stuiver, Minze and Kra, Renee, eds, Internatl radiocarbon conf, 10th, Proc: Radiocarbon, v 22, no. 3, p 947-949.

Damon, P E, Long, Austin, and Ferguson, W C, 1974, Dendrochronologic calibration of the radiocarbon time scale: Am Antiquity, v 39, p 350-366.

Damon, P E, Long, Austin, and Wallick, E I, 1972, Dendrochonologic calibration of the carbon-14 time scale, in Rafter, $\mathrm{T} \mathrm{A}$ and Grant-Taylor, $\mathrm{T}$, eds, Internatl radiocarbon dating conf, 8th, Proc: Wellington, Royal Soc New Zealand, p A28-A43.

de Jong, A F M, Mook, W G, and Becker, Bernd, 1979, Confirmation of Suess wiggles: 3200-3700 BC: Nature, v 280, p 48-49.

Lerman, J C, Mook, W G, and Vogel, J C, 1970, C-14 in tree rings from different localities, in Olsson, I U, ed, Radiocarbon variations and absolute chronology, Nobel symposium, 12th, Proc: New York, John Wiley \& Sons, p 275-301.

McKerrell, H, 1975, Correction procedures for C-14 dates, in Watkins, T, eds, Radiocarbon: Calibration and prehistory: Edinburgh, Edinburgh Univ Press, p 47-100.

Michael, H N and Klein, Jeffrey, 1979, An international calibration for radiocarbon dates: MASCA Jour, v 1, no. 2, p 56-57.

Michael, H N and Ralph, E K, 1972, Discussion of radiocarbon dates obtained from precisely dated Sequoia and Bristlecone Pine samples, in Rafter, T A and Grant Taylor, T, eds, Internatl radiocarbon dating conf, 8th, Proc: Wellington, Royal Soc New Zealand, p 28-43.

Mosteller, F and Tukey, J W, 1977, Data analysis and regression: a second course in statistics: Reading, Mass, Addison-Wesley, 588 p.

Olsson, I U, ed, 1970, Radiocarbon variations and absolute chronology, Nobel symposium, 12th, Proc: New York, John Wiley \& Sons, 657 p.

Ralph, E K and Klein, Jeffrey, 1979, Composite computer plots of ${ }^{14} \mathrm{C}$-dates for tree-ring dated bristlecone pine and Sequoia, in Berger, Rainer and Suess, H E, eds, Radiocarbon dating, Internatl radiocarbon conf, 9th, Proc: Berkeley/Los Angeles, Univ California Press, p 545-553.

Ralph, E K and Michael, H N, 1970, MASCA radiocarbon dates for Sequoia and bristlecone-pine samples, in Olsson, I U, ed, Radiocarbon variations and absolute chronology, Nobel symposium, 12th, Proc: New York, John Wiley \& Sons, p 619-624.

Ralph, E K, Michael, H N, and Han, M C, 1973, Radiocarbon dates and reality: MASCA Newsletter, v 9, p 1-20.

Stuiver, Minze and Quay, Paul D, 1980, Changes in atmospheric ${ }^{14} \mathrm{C}$ attributed to a variable sun: Science, v 207, p 11-19.

Stuiver, Minze and Suess, H E, 1966, On the relationship between radiocarbon dates and true ages: Radiocarbon, v 8, p 534-540.

Suess, H E, 1955, Radiocarbon concentration in modern wood: Science, v 122, p 415-417. 1967, Bristlecone pine calibration of the radiocarbon time scale from 4100 BC to 1500 BC, in Radioactive dating and methods of low-level counting: Vienna, IAEA, p 143-151.

1970 , Bristlecone pine calibration of the radiocarbon time scale 5200 BC to the present, in Olsson, I U, ed, Radiocarbon variations and absolute chronology, Nobel symposium, 12th, Proc: New York, John Wiley \& Sons, p 303-311. 
Switsur, V R, 1973, The radiocarbon calendar recalibrated: Antiquity, v 47, p 131-137. Tukey, J W, 1977, Exploratory data analysis: Reading, Mass, Addison-Wesley, 688 p.

Velleman, P F, 1977, Robust nonlinear data smoothers: Definitions and recommendations: Natl Acad Sci, USA, Proc, v 74, no. 2, p 434-436.

de Vries, Hessel, 1958, Variation in concentration of radiocarbon with time and location on earth: Koninkl Nederlandse Wetensch Proc, ser B, v 61, p 94-102.

1959, Measurement and use of natural radiocarbon, in Abelson, P H, ed Researches in Geochemistry: New York, John Wiley \& Sons, p 169-189.

Wendland, W M, and Donley, D L, 1971, Radiocarbon-calendar age relationship: Earth Planctary Sci Letters, v 2, p 135-139. 